
anthropocentrism"

Nicolas Treich 


\title{
The Dasgupta Review and the problem of anthropocentrism
}

\author{
Nicolas Treich* \\ Toulouse School of Economics, INRAE, University Toulouse Capitole, Toulouse, France \\ February 2022 \\ Forthcoming in Environmental and Resource Economics
}

\begin{abstract}
As is customary in economics, the Dasgupta Review on the economics of biodiversity adopts an anthropocentric approach: that is, among the millions of species on Earth, the Review accords a moral value to only one species; ours. Building on the literature in ethics, I explain why it is morally problematic to assume that other species - at least, sentient animals - only have an instrumental value for humans. The Review defends its approach, but I advance counter arguments. I highlight that preserving the diversity of life in ecosystems is not the same as taking care of the wellbeing of sentient species living in those ecosystems. Some biodiversity policies, such as protecting the blue whale or reducing meat consumption, largely satisfy both anthropocentric and non-anthropocentric objectives. Other policies, such as the reintroduction of wolves or the eradication of invasive species, induce conflicts between these objectives. I finally discuss why the anthropocentric view remains prevalent in the research on biodiversity and present some potential non-anthropocentric research directions
\end{abstract}

JEL codes: Q51, Q20, Q18, I30, Z00

Keywords: Biodiversity, environmental economics, anthropocentrism, animal welfare, sentience, conservation.

\footnotetext{
* Acknowledgements: I thank Lea Stapper and Julie Maurin for their excellent research assistance as well as the editor (Ingmar Schumacher) and two anonymous reviewers. Thanks also to Heather Browning, Florence Burgat, Alexis Carlier, Marion Desquilbet, Romain Espinosa, Elise Huchard and Sara Crompton Meade for useful comments and discussions. I acknowledge the research funding from the ANR under grant ANR-17-EURE-0010 (Investissements d'Avenir program) and from the chairs FDIR and SCOR "Market risks and value creation" at TSE-Partnership. Email: nicolas.treich@inrae.fr. Address: Toulouse School of Economics, 1 Esplanade de I'Université, 31080 Toulouse, France.
} 
"Ta justice, c'est ton utilité, ton plaisir, ton caprice", L'homme et la Couleuvre, Jean de La Fontaine (1621-1695). ${ }^{1}$

"In nothing does man, with his grand notions of heaven and charity, show forth his innate, low-bred, wild animalism more clearly than in his treatment of his brother beasts. From the shepherd with his lambs to the red-handed hunter, it is the same: no recognition of rights only murder in one form or another." John Muir (1838-1914)

\section{Introduction}

The Dasgupta Review on the economics of biodiversity (Dasgupta, 2021) is a masterly work. There is little doubt about that, as suggested, for instance, by initial enthusiastic reactions of scientists and policy makers, ${ }^{2}$ some early published commentaries (Groom and Turk, 2021) and other contributions in this Special Issue. Nevertheless, I argue in this paper that there is a problem with it; that is, the Review adopts an anthropocentric approach. This means that the wellbeing of human beings is all that matters for the social objective. In other words, the Review concerns the value of biodiversity for humans only. This paper attempts to articulate why this is a problem and can be interpreted as a call to broaden the research agenda of the economics of biodiversity in the future.

Concisely, I argue in Section 2 that it is not acceptable to assume that other species - at least, sentient animals - only have an instrumental value for humans. ${ }^{3}$ This argument has a solid foundation in ethics (Bentham, 1780; Singer, 1975, 2011; Regan, 1983). The Review attempts to defend its anthropocentric position, but I argue in Section 3 that the defence is not convincing. With a few supporting examples, I explain in Section 4 why preserving biodiversity while adopting an anthropocentric view is different from preserving it under a non-anthropocentric view. In particular, the former approach is not a minimal version of the

\footnotetext{
${ }^{1}$ Translation by the author: "Your justice is your utility, your pleasure, your whim" in The Man and the Snake by Jean de La Fontaine.

${ }^{2}$ See, e.g., https://www.gov.uk/government/publications/final-report-the-economics-of-biodiversity-thedasgupta-review/the-economics-of-biodiversity-the-dasgupta-review-reactions, or https://deframedia.blog.gov.uk/2021/02/02/defra-group-reaction-to-the-dasgupta-review/.

${ }^{3}$ For simplicity, here and in the rest of the paper, I write "animals" to denote "non-human animals".
} 
latter, as suggested in the Review. In Section 5, I argue that reducing meat consumption largely aligns both anthropocentric and non-anthropocentric objectives. In Section 6, I reflect on why (environmental and resource) economists adopt an anthropocentric approach as do some other environmental scientists. Finally, in Section 7, I delineate some nonanthropocentric research directions before concluding.

To comprehend the problem, note that the Review puts forward the Net Primary Productivity as a biodiversity measure, which is a flow of biomass (Chapter 2). ${ }^{4}$ This metrics makes sense when biodiversity has an instrumental value, however, it essentially assumes that what matters overall is a certain quantity of life, not its quality (Sekar and Shiller, 2020). In fact, there are no common biodiversity metrics (listed on page 77 ) that truly capture the wellbeing of different species. As a result, relying on those metrics for designing our environmental policies may have morally troublesome consequences. As McSchane (2018) says: "To see the force of this point, consider what difference it would make if we thought the aim of human morality was only to ensure that certain kinds of people exist, but with no attention to the quality of their lives." In this paper, I advocate for a change in mindset: we should protect current ecosystems to the extent that this enhances the global welfare of humans and of sentient animals involved in these ecosystems.

Adopting such a perspective leads us to reconsider conventional ways of thinking about biodiversity. Environmental protection associations and experts usually emphasize biodiversity loss by pessimistically presenting the decrease in the number of species or their disappearance (Ceballos et al., 2015; IPBES, 2019; WWF, 2020). The maintenance of ecosystems is implicitly presented as "a good thing", while the disappearance of some species is viewed as "a bad thing", especially if this is linked to human action. First, however, from the victim's viewpoint, note that dying from a natural cause or "unnaturally" from a human cause makes no difference. More profoundly, the loss of biodiversity in an ecosystem has no moral significance per se. Only if the loss can be linked to a change in the welfare of

\footnotetext{
${ }^{4}$ Here and in the rest of the paper, when I provide a page or chapter number in parentheses, this refers to the location of the corresponding text in the Review.
} 
sentient species living in that ecosystem does it have moral significance, however, that link is not usually studied and often not even discussed. ${ }^{5}$

This paper thus emphasizes the need to carefully consider our wellbeing footprint when designing biodiversity policies. It builds on animal ethics, which has become an important subfield in philosophy and has inspired several philanthropic and political movements. I assume that the key criterion for moral consideration is that of "sentience". My approach could be qualified as "sentientist" or "pathocentric" in its opposition to anthropocentrism. Other non-anthropocentric approaches could have been considered; see Section 2. Obviously, there is still some disagreement over exactly which species are sentient, which ones are morally important, and how their interests must be weighed against human interests. However, the key point is that sentient animals should at least be objects of some moral consideration. In this paper, I define "global welfare" to mean the welfare of humans and of sentient animals. Thus, my main criticism of the Review is that it is solely concerned with human welfare, while I argue it should be (more) concerned with global welfare. I now present my motivation for this paper more precisely. First, I want to stress that the main message of this paper is certainly not novel. It is well known that economics almost always adopts an anthropocentric approach (Johansson-Stenman, 2018; Budolfson and Spears, 2020; Carlier and Treich, 2020). This problem has long been recognized, though it has not been addressed, even in environmental and resource economics ( $\mathrm{Ng}$, 1995; Fleurbaey and Leppanen, 2021). Hence, it is of no surprise that the Review also adopts a standard anthropocentric approach. To be fair, since there exist very little empirical evidence or theoretical work that integrate animal welfare in (environmental and resource) economics, it would have been very difficult for the Review to adopt a non-anthropocentric approach. As a result, the reader may question why anthropocentrism is once again challenged by means of a critical discussion of the Dasgupta Review.

There are several reasons for this. The first is strategic: it is a matter of visibility and influence. Although the fact that anthropocentrism in economics is well known, the

\footnotetext{
${ }^{5}$ I am somewhat unfair here in order to highlight my point. Several associations and experts emphasize the role of humans in biodiversity loss because this role is indeed central, and perhaps because they want to trigger actions. Moreover, by pointing out the rapid decline in biodiversity, they stress that this alarming trend can hardly be attributed to a natural change in ecosystems (WWF, 2020). This relates to the Anthropocene rhetoric (Seddon et al., 2016).
} 
profession has largely ignored this problem and continues to do so. However, because the Review is a prominent and high-quality document led by a first-class economist, this provides an opportunity to challenge the status quo and to make the problem more prominent. Indeed, the Dasgupta Review may become the state of the art of the economics of biodiversity for years to come and may be highly influential in the policy making arena. Hence, my current critique might benefit from the notoriety of the Review (and of this Special Issue) with the hope that some warnings regarding the limits of anthropocentrism will be heeded. By presenting some basic ideas and providing some key references, it is hoped that this paper will stimulate some scholars, perhaps in the younger generation, to develop their own non-anthropocentric works in the future.

The second reason concerns the topic in itself; namely, biodiversity. In essence, the Review is about preserving the "diversity of life" (page 4). There are millions of species on Earth, thus it is quite striking that the Review accords a moral value to only one species; ours. But there is more to say on this point. The Review is essentially a study of the preservation of plants and animals, yet there is a radical difference between the two. Unlike plants, most animals have a brain and a nervous system. Like us, they can feel pain and pleasure, and they have feelings and emotions. In other words, animals are sentient. The Review, however, overlooks this central distinction between animals and plants when it defines the normative objective, as it draws a moral line with humans on one side and both animals and plants on the other. I consider this to be a major flaw, as this fundamentally overlooks one of the most central aspects of what constitutes the diversity of life on Earth; namely, the diversity of subjective experiences.

The third reason is that the Review explicitly recognizes the problem of anthropocentrism and attempts to defend its approach accordingly. Admittedly, this normative discussion is relatively brief in the Review compared to its total length, as it covers only a couple of pages out of more than 600 pages. However, this is remarkable in itself, especially given that the tradition in economics is to adopt an anthropocentric view without excuse or discussion (for example, consider economic textbooks). Instead, the Review openly recognizes the problem as early as in Chapter 1 and discusses it in some detail in Chapter 12 in particular. Therefore, the Review opens the debate on anthropocentrism, and I consequently take this as an invitation to discuss the issue more comprehensively. 
A fourth reason is more personal and relates to my own interests (and biases). My current areas of research mainly concern the economics of the environment, food, and animal welfare, which also reflects some of my personal aspirations. This paper is thus likely the result of a level of dissatisfaction I have with the Review, ${ }^{6}$ and more generally, with the position of many environmentalists who unquestioningly ignore the wellbeing of animals. Of course, I understand that the Review cannot extensively discuss all viewpoints given the multiple topics addressed. Indeed, the Review is largely "orthodox" (Groom and Turk, 2021), focusing on mainstream knowledge and results, often leaving some marginal views aside. ${ }^{7}$ I also note, however, that the Review is somewhat bold on a number of issues, such as that of the limits-to-growth concept or fertility issues. I am thus disappointed that it remains conservative regarding one of its most central aspects; namely, the adopted normative approach.

The final reason for this paper concerns the academic and political implications of the Review. Schematically, three disciplines are concerned: the first is economics; the second is ecology/conservation; and the third is animal ethics. Importantly, the Review provides an excellent bridging of the first two disciplines but ignores the third. I believe that this may impair the intellectual contribution, but also the success of some interventions on the ground (Greggor et al., 2016). To take one example, when conservation authorities in Italy tried to eradicate a population of non-native squirrels, a court action by animal associations delayed the programme long enough so that the species became too established for eradication to be feasible (Fraser, 2010). Further, many citizens are concerned by the environment, by animal welfare, and often by both. Indeed, conservation campaigns often "play on the emotions" triggered by the harm caused to animals. It can thus be important to acknowledge and consider animal ethics when biodiversity policies are studied and implemented.

\footnotetext{
${ }^{6}$ After reading the published interim version of the Review in 2020, Lea Stapper and I wrote a comment to the Review's managing team about the problem of anthropocentrism. I do not know if the feedback we provided affected the final content of the Review. In Spring 2021, I also attended an online presentation by Partha Dasgupta organized by the Toulouse School of Economics and the Society for Benefit Cost Analysis, where I brought up the problem during the stimulating discussion.

${ }^{7}$ This justification is mentioned explicitly in the Review (page 69): "Which is why it will pay to build the economics of biodiversity on the back of an anthropocentric viewpoint. Doing so will, moreover, enable us to stay close to the way environmental and resource economics in general and the economics of climate change in particular has been fashioned by economists."
} 


\section{The problem}

The Review clearly states that it adopts an anthropocentric view. For instance, it states in Chapter 1 (page 49): "In the chapters that follow, we mostly adopt an anthropocentric viewpoint - the value of biodiversity is studied in terms of its contributions to humanity, that is human well-being." It is explained elsewhere in this chapter that this is the view adopted in almost all of the Review (page 36): “...we will find that it pays to build the study of biodiversity's value from an anthropocentric perspective and then add non-anthropocentric perspectives to give further urgency to repairing our relationship with Nature (see Chapter 12)." In the preface (pages 5-6), Partha Dasgupta, sets the scene by citing a list of examples of various beneficiaries from biodiversity preservation such as farmers or residents of mega cities and finally "people everywhere today"; however, it is revealing that he does not mention any potential non-human beneficiaries.

Essentially, the Review assumes that non-human species do not have an intrinsic value, rather, they only have an instrumental value for humans. These species can be for our food or our medicine, for instance, or they can generate a value for tourism activities (Chapter 12). Perhaps more importantly, they have a function within their own ecosystems, for instance, through pollination, seed dispersal, photosynthesis etc., and they in turn increase the productivity and stability of the ecosystem as a whole (pages 68,74 ). Consequently, much of the Review concerns the complex phenomena of interactions and resilience that occur in Nature. Interestingly, one of the key message of the Review is to emphasize that "we are embedded in Nature" (pages 4, 27, 45, 47, 49, 119, 127, 137, 140, 186, 310, 312, $487,498)$. The "we" used here and elsewhere means human beings. That is, the message is that we, humans, are not external to Nature; we are part of it. Importantly, there is a striking dissonance between this all-encompassing message and the adopted normative view. Indeed, this view implies that humans are precisely not the same as the rest of Nature, as we emerge as the only source of moral value.

In summary, my central point is that the normative position adopted in the Review is morally dubious. Anthropocentrism may be viewed as a corner moral case where only humans have any moral value. Fleurbaey and Leppanen (2021) claim, for instance, that "...anthropocentrism in normative concepts is suspect, unfounded, ominously similar to the old religious and racist doctrines that gave the White Christian Man the right to own the 
Earth, and apparently too weak as a normative compass to fight pervasive destruction in the age of mass extinction." Some would qualify the Review's position as "speciesist" (Singer, 1975). Speciesism means that there is an unjustified disadvantageous consideration of those not classified as belonging to a certain species. Given that the unfavoured species are all non-human species, one can call this approach "anthropocentric speciesism" (Horta, 2010b). To understand the problem with anthropocentric speciesism, it is useful to briefly recall the longstanding thinking in ethics as to what justifies moral consideration.

A key argument to justify anthropocentrism is human exceptionalism (Gruen, 2017). Although humans are exceptional in many ways, the once popular belief that it is unscientific to attribute emotions or thoughts to animals is now viewed as inconsistent, with support from evolutionary theory, experimental evidence, and any reasonable burden of proof (Sekar and Shiller, 2020). While various beliefs and religions emphasize the human-animal divide, science now clearly indicates that there are biological continuities between humans and animals. This modern view in science was anticipated by many philosophers. JeanJacques Rousseau with his concept of "sensibilité", and Voltaire when criticizing Descartes' animal machine, but especially the early utilitarians, such as Jeremy Bentham, John Stuart Mill, or Henry Sigdwick who were particularly influential in animal ethics (JohanssonStenman, 2018; Carlier and Treich, 2020). Bentham (1780) with his famous line "...the question is not, Can they reason? Nor, Can they talk? But, Can they suffer?", suggested that there is no moral justification to ignore the suffering of an animal, and that this suffering should therefore enter into utilitarian calculation

More generally, the ability to experience positive or negative states, such as happiness and suffering, is viewed as a fundamental criterion for moral consideration. This view is consistent with the conclusion of a large body of modern philosophers, regardless of their tradition, who have expressed an opinion on this matter (Carlier and Treich, 2020; McShane, 2018; Sebo, 2021). To describe this ability, a key word nowadays is "sentience". Although there is no universally agreed definition of sentience, it essentially means the ability to feel or to have subjective experiences. For instance, Broom (2014) defines sentience as "having awareness and cognitive ability necessary to have feelings". Hence, the notion of sentience is intimately linked to those of "self-awareness" or "consciousness". 
The next question is: which species are sentient? Basic neural functioning across vertebrate species reveals strong similarities in experiential capacities. All studied mammals share basic emotional systems, including joy, fear, grief, parental nurturance, and playfulness (Sekar and Shiller, 2020). Overall, there is strong evidence of sentience in mammals and fish, but also birds and cephalopods (Baars, 2001; Edelman et al., 2005; Brown, 2015). This is embodied in the famous Cambridge Declaration on Consciousness in 2012: “...the weight of evidence indicates that humans are not unique in possessing the neurological substrates that generate consciousness. Non-human animals, including all mammals and birds, and many other creatures, including octopuses, also possess these neurological substrates" (Low et al., 2012, p. 2).

A wide variety of species are in fact capable of experiencing physical and emotional pain and executing some cognitively complex tasks. It has been shown that various animal species can, for example, design tools, use vocal communication, including symbolic communication forms of proto-syntax, manage long-term social relationships, have systems of conflict resolution, and impute mental states to others (Webb et al., 2020). Other animals, in particular insects and some molluscs, have a relatively smaller or less centralized nervous system and it is not clear if they are sentient. Nonetheless, due to scientific uncertainty about their sentience, there is an argument to apply the precautionary principle and put at least some moral weight on these species as well. ${ }^{8}$

The situation differs for plants. Although many popular writers and some life scientists (such as the proponents of the recent "plant neurobiology") have suggested that plants have emotions and possess a form of cognition, plants are radically different from animals. They do not have a brain and a nervous system. According to the best evidence, plants cannot learn, and they do not seem to possess consciousness, feelings, and intentionality. In a recent synthesis paper, Taiz and co-authors (2019) conclude that "...the likelihood that plants, with their relative organizational simplicity and lack of neurons and brains, have consciousness to be effectively nil". There is a basic evolutionary reason for this: as plants are immobile, it would be inefficient for them to possess these energy-intensive faculties. Along

\footnotetext{
${ }^{8}$ Some advance that crustaceans, spiders, and insects are sentient (Ginsburg and Jablonka, 2019). In any case, when these species are very numerous, such as insects, even a low probability of sentience should matter for the decision (Sebo, 2021).
} 
this line, Ng (1995) argues that to be sentient, a species has to be "plastic"; namely, it must possess the flexibility to choose different responses for a given situation. ${ }^{9}$ All hard-wired responses are non-plastic. Following a set of logical arguments, $\mathrm{Ng}$ concludes that "...all conscious species are plastic and all plastic species are affectively sentient".

Before turning to the next section, it is important to add some words of caution regarding my contribution, and in particular its specificity and limitation. First, as stressed above, the key criterion I consider for moral consideration is sentience. Hence, my approach is essentially "sentientist", or "pathocentric". Note, however, that it is neither "biocentric" (i.e., a life-centred ethic including all living organisms) nor holistic or "ecocentric", which are important approaches in environmental ethics (see below). Although the sentientist view rests on solid ground in animal ethics, it can be criticized. In particular, it may lead to the over-prioritization of more sensitive individuals, within and across species. This is reminiscent of the well-known Nozick's reference to "utility monsters"; that is, those individuals who can transform resources into happiness more easily and would, as a result, receive higher priorities. See Fleurbaey and Leppanen (2021) for a discussion and a moral view that is more encompassing.

I also adopt an approach that is "consequentialist", "welfarist" and "individualist", as in Norwood and Lusk (2011) and Johansson-Stenman (2018), for instance. That is, I essentially assume that the ultimate policy goal should be to select the actions that generate the best consequences in terms of the welfare of all sentient individuals. Except for the inclusion of animals in the moral circle, this approach is the standard one in economics (Fleurbaey and Maniquet 2011; Adler, 2012). It is not the object of this paper to defend this approach nor to discuss various other normative possibilities. I use it here for simplicity and especially because it proposes a simple extension of the standard economic setting. Moreover, this approach is often considered as the leading alternative to anthropocentrism (Beausoleil, 2020), and is consistent with some utilitarian interpretations of anti-speciesism, a leading theory in animal ethics (Singer, 1975, 2011; Horta, 2010a, 2010b; Johansson-Stenman, 2018;

\footnotetext{
${ }^{9}$ Note that the term "plastic" here should not be understood as it is often defined in biology. Namely, it is not about phenotypic plasticity, as immobile organisms such as plants usually display greater phenotypic plasticity than mobile organisms (i.e., most animals).
} 
Espinosa and Treich, 2020). Furthermore, other non-consequentialist approaches may lead to similar conclusions (Sebo, 2021).

Finally, it is important to emphasize that in the context of environmental ethics, much emphasis has been given to "collectivist" notions, as opposed to individualist ones. These approaches (often termed holistic or ecocentric), attribute a moral value to species, communities, or ecosystems (Leopold, 1949; Callicott, 1989; Taylor et al., 2020; see Chapter 12 in the Review). They focus on Nature as a whole and usually strive to maintain ecosystem composition and ecological processes. They tend to emphasize the network aspects of life rather than the importance of individual organisms. These non-anthropocentric approaches have been influential within intellectual movements of biodiversity protection, however, they have also been strongly criticized in animal ethics (Feinberg, 1974; Regan, 1983; Horta, 2010a; Singer, 2011). Obviously, these critiques do not mean that the case for the protection of ecosystems is not strong, but rather that it remains to be shown that ecosystems have a moral value beyond sustaining sentient life in them. In any case, this raises a central question that is far beyond the scope of this paper: how to reconcile environmental ethics and animal ethics?

\section{The defence}

As mentioned in the Introduction, the Review briefly defends its normative position. It says that (page 49) "...there are nevertheless good reasons for concentrating on what one may call the instrumental value of biodiversity. One reason is that there are innumerable systems of thought that go beyond an anthropocentric perspective. Many people argue that life itself has intrinsic value, never mind that only a few among the 8 to 20 million species (of eukaryotes) on Earth are known to feel, never mind to have self-awareness. There are also many systems of belief - alas, all too readily overridden by cosmopolitan society - in which objects that to the cosmopolitan are inanimate, are sacred. They may house life, but they are not life; nevertheless, they are sacred. Uluru in Australia is a famous example. It is sacred to the Pitjantjatjara, the Aboriginal people of the area surrounding it. And there is the river Ganges, sacred to Hindus (Box 2.8). But the narratives underlying their sacredness differ." I believe that this defence is problematic for several reasons. First, I understand that by stressing that there are "innumerable systems of thought" or that there are "many systems 
of belief', it is suggested that there exist so many worldviews that one cannot account for all of them. I agree with this idea. However, I also believe that this does not justify readily ignoring all alternative views and focusing only on one of them: the anthropocentric view. Why not also select some non-anthropocentric views that seem particularly interesting or relevant? Second, the argument that only a few species "are known to feel" or "have selfawareness" is turned on its head here. Since these "few" species include mammals, birds, fish, and cephalopods (as argued before), this concerns a large range of species and, in turn, billions of animals. This can hardly justify ignoring the intrinsic value of these animals.

Besides which, if there is scientific uncertainty regarding the sentience of other animals, such as insects, this defensive view does not justify fully ignoring their intrinsic value but rather recommends a precautionary approach, as already argued.

This point is somewhat reinforced later (page 312) when the Review discusses the "moral standing" of ecosystems. It says that "...it is important to note that this takes place at the level of the ecosystem, rather than of the individual plants and animals that make it up. The reason for this is that there are certain hard limits on the sophistication of plants and animals that do not possess a grammatical language. They can learn things in a 'Skinnerian' fashion, choosing to do what leads to rewards and avoid what leads to harms, but because they cannot conceptualise the world they cannot imagine or respond to things they have not yet experienced. The most they could possibly achieve is inference by induction, not the kind of creative reasoning that is involved in creating a self and responding to reasons. Most of the development of plants and animals therefore happens at the level of the population". This part is problematic in light of scientific knowledge regarding the cognition and the behaviour of animals, as briefly described in the previous section. ${ }^{10}$ Skinnerian positions have become marginal since the surge of cognitive ethology, precisely built in opposition to the Skinnerian tradition (Griffin, 1978). Further, it is not clear why possessing grammar is relevant for moral standing, rather than the capacity to have subjective experiences, for instance. Again, it is questionable to merge animals and plants in terms of an ability to conceptualize the world and be self-aware.

\footnotetext{
${ }^{10}$ On grammatical language, and the scientific uncertainty on this issue, see, for example, ten Cate (2016).
} 
Third, the former paragraph cites a small number of examples of sacred places, such as Uluru for the aboriginal people of Australia or the Ganges River for Hindus. The example of the Ganges is further developed in Box 2.8, where it is said that the "...the river Ganges is a goddess (she is called Ma Ganga)" but that "is one of the most polluted rivers in the world". Moreover, it adds (page 69): "Many people say, however, that the pollution is illusory, that being celestial, Ma Ganga is incapable of being polluted. Accommodating conflicting imperatives is universal practice, and we frequently accomplish it by rationalising our beliefs. Which is why it will pay to build the economics of biodiversity on the back of an anthropocentric viewpoint." Here, the Review refers to a "holist" or "animist" approach, that gives moral value to the non-living, such as a rock or a river. Yet, I am not certain why this reference justifies the anthropocentric approach it adopts. Perhaps, by evoking some magical/mistaken beliefs of illusory pollution, and by using the expression "rationalising our beliefs", the Review suggests that it appears better to ignore those beliefs because they are irrational. If that is the point, it is puzzling. First, this argument seems somewhat strange since economics usually assumes that the consumer/citizen is sovereign and that subjective beliefs matter for welfare (cf. Savage's theory reviewed in Chapter 5). This is the standard approach in environmental valuation. Besides, within that approach, a possibility would have been to emphasize that many people actually do care about animal wellbeing, as many studies have shown (Norwood and Lusk, 2011). Instead, the Review essentially ignores the issue of animal wellbeing. Moreover, this argument seems unfair since, again, an important body of work in philosophy challenges anthropocentrism. In addition, such a justification seems to place the Western system of values above other systems without clear supportive reasoning.

However, the most important reason for why the above defence is unconvincing is the following. All of these arguments about people's beliefs remain anthropocentric; that is, these arguments relate to what some groups of people somewhere in this world think about how to account for Nature (e.g., the fact that a river or a rock in their proximate environment is sacred), rather than about how Nature should be accounted for intrinsically. It is correct and logical of course to postulate that Nature can enter into the social objective because some people care about it, but that is only an indirect way of assigning a value to Nature through the human lens. As said above, such an approach is standard in economics, 
for instance, when estimating the willingness to pay to protect the environment (cf. the value of existence, Chapter 12). Nevertheless, this approach remains anthropocentric, and can thus hardly be used to dismiss non-anthropocentric views. As explained in the previous section, sentient animals deserve moral consideration, and this is true independent of the beliefs of people about this. In the extreme, even if people care nothing for animals, the wellbeing of animals still matters for global welfare.

Finally, the Review goes on to add the following (page 68): "There is a second reason. If we are able to show, as we intend to in the Review, that biodiversity is of the utmost value to humanity, and that because we are embedded in Nature, gradual biological extinction will hasten our own extinction, then for purely anthropocentric reasons we would wish to preserve and promote it. But if biodiversity is worth preserving and promoting for purely anthropocentric reasons, it would be even more deserving of protection and promotion if it had sacred status. Therein lies the advantage of a limited point of view." This additional defence thus suggests that the anthropocentric view is a sort of minimal, or "limited", account of the value of Nature, in the sense that the argument behind measures taken to improve human wellbeing would be strengthened when also taking non-human welfare into account. In other words, this suggests that humans by preserving biodiversity to maximize their own interests would also satisfy non-anthropocentric objectives. This could be true in many instances, as preserving biodiversity may clearly enhance the wellbeing of wild animals (Beausoleil, 2020), thus generating some global welfare improvement. In other words, the interests of humans, wild animals and biodiversity often coincide.

However, I disagree with this idea as a general rule. Having a healthy ecosystem is not the same as having "happy" animals in general. And what is good for us is certainly not always good for other non-human beings. In contrast, I argue that preserving biodiversity while adopting an anthropocentric view might sometimes differ greatly from preserving it under a non-anthropocentric view. I call this the "misalignment issue" and discuss it separately in the next section with some examples. This idea relates to the narrative that humans may provide good stewardship to Nature in general. Fleurbaey and Leppanen (2021) eloquently refute this narrative: "The dramatic history of colonialism and slavery suggests that when a subpopulation grants itself overall responsibility over a larger population, and considers itself to be the best steward of the whole, it actually directs most resources toward its narrow 
interests and can be so oblivious of the interests of the 'other' as to put them into a state of inferiority and dependence from which it takes generations to recover. Even genocide has proved to be possible in this context. This is exactly what we now observe with the extinction of many species under the pressure of human invasive and careless activities, and the reduction of many animals into a state of complete dependence, even in shelters designed to protect them."

\section{The misalignment issue}

Using a few examples, in this section I show that anthropocentric and non-anthropocentric views may diverge and in turn lead to the recommendation of different biodiversity management policies.

\subsection{Reintroduction of wolves}

The question of the reintroduction of predators often generates intense scientific and political debate. This debate is often framed as a conflict between the benefit for the biodiversity and the cost to residents, such as farmers whose animals can be negatively affected by the presence of predators. Other consequences of the reintroduction policy might also matter, such as the impact on hunters. In this section, I emphasize an aspect that is usually overlooked: the wellbeing of prey.

I discuss here an emblematic case, namely the reintroduction of wolves in the USA. The Review mentions (page 455) “...the reintroduction of wolves into Yellowstone National Park, USA, to help manage increasing populations of elk". Relatedly, the Review (page 75) formally studies the management of "...ecosystem architecture by considering a three-level trophic web: plants, herbivores and carnivores", emphasizing that the "...removal or addition of trophic levels ('biomanipulation') achieves desired states of primary productivity". The reintroduction of predators is indeed often justified by the trophic cascade it produces, which can help biodiversity to thrive.

In the widely known case of the reintroduction of wolves to the Yellowstone National Park, the main problem was that elks were overgrazing, and in particular were eating aspen shoots so that these trees could not reproduce. Wolves were reintroduced in 1995 in the park after 70 years of absence in order to reduce the elk population. My focus here is that the reintroduction policy had a direct impact on sentient animals (see Horta, 2010c for a 
thorough discussion). Indeed, one wolf kills on average about 20 elks per year, so the policy reduces the life expectancy of elks significantly. Moreover, the key impact is deterrence: once wolves are present, elks tend to hide in the woods and source their food there, resulting in a nutritional deficit. This policy thus generates an important harm on the elks, both in terms of survival and wellbeing. ${ }^{12}$

Various studies have demonstrated that exposure to predators or predator cues can have permanent effects on their prey, with associated physiological stress effects that are comparable to chronic stress in humans (Clinchy et al., 2012). Indeed, predator reintroduction policies have also been called the "ecology of fear" (Ripple and Beschta, 2004; Horta, 2010c). Of course, given the complexity of trophic cascade impacts on the ground, a thorough analysis of the various implications of a reintroduction policy (and its counterfactual) must be performed on a case-by-case basis. We must also consider that the overpopulation of prey may sometimes lead them to starve to death, for instance during a drought, so it is not always clear that death from predation is necessarily worse. In any case, reintroducing predators certainly has an important impact on the wellbeing of prey (in particular, through the deterrence effect) beyond its various effects on ecosystems and subsequently on humans, and that therefore there is no moral justification to systematically ignore this impact.

\subsection{Endangered species}

Many plant and animal species are at risk of extinction, with about $25 \%$ listed according to the International Union for Conservation (IUCN) Red List of Threatened Species and 60\% in the primate order, for instance (Estrada et al., 2017). Biodiversity management policies often consist of legally protecting species that are on a list of endangered or are a vulnerable species (see Ando and Langpap, 2020 for a recent synthesis of the economics of these policies). The Review addresses this issue on many occasions; for instance, when it discusses the IUCN Red List index (page 78), the problem of deforestation as a primary cause of species' extinction (Box 4.1), the Endangered Species Act (ESA) (page 198), and the links between species' extinction and international trade (Boxes 15.5 and 18.4).

\footnotetext{
12 One may wonder: what about the impact on the wellbeing of wolves? Given that the wolves were captured in Canada, transported, and then released in a novel environment, this impact may not be positive either.
} 
Interestingly, the Review also formally studies the problem of "saving the blue whale" (Annex 13.2). After presenting the formal exercise based on Spence's model, the Review adds the following: "Many would insist blue whales possess an intrinsic value, let alone an existence value many people would regard them to have. If we add those values to the commercial value that Spence considered, the long-run stationary population humanity should strive to attain for blue whales would be higher still. Which is why Spence's formulation, repugnant though it would appear to many people, is of enormous value. It provides us with a biased estimate of a whale's worth, and this is useful information. His analysis recommended preservation of blue whales solely on commercial grounds. But if preservation is the right policy when the accounting price of blue whales is estimated from their market price only after they have been slaughtered, the recommendation would be reinforced if their intrinsic worth, as stock, were added." Here, the Review argues that accounting for the commercial value of blue whales provides a lower bound of the total value, as it may in addition include the "...existence value many people would regard them to have." As a side remark, note first that this argument sounds paradoxical. Although it is of course correct that it may be optimal for commercial reasons to prevent the overexploitation of whales, the commercial and existence values do not really add up. Indeed, if people prefer whales to be alive, as suggested in this last sentence, then they should not be slaughtered and thus they lose their commercial value.

The main problem with this argument based on the existence value for humans is that it is, once again, anthropocentric; namely, it is about how people value blue whales. This view is in fact the common approach in the economics of species' preservation. For instance, Metrick and Weitzman (1998) find in a simple model of the famous Noah's ark allegory that the ranking of preserved species should depend on the utility of a species, namely the commercial value as well as the value of existence which can capture people's emotional reactions to a given species. Metrick and Weitzman's empirical analysis of ESA decisions indicate that the proxy (i.e., charismatic megafauna) capturing this utility has a large effect on those decisions, whereas other determinants, such as survivability, diversity, and costs do not matter as much.

The evident concern with this approach is that people preferences may not reflect the real utility gains in terms of biodiversity, as typically estimated by conservation experts (Martin- 
Lopez et al., 2008). More importantly for my purpose, peoples' preferences may not reflect the wellbeing gain for the protected species. For instance, there is evidence that our empathy and compassion toward other species decreases with phylogenetic distance (Miralles et al., 2019): we prefer to save a gorilla more than a beluga whale, more than a scallop, and more than a fungus. This finding is consistent with a preference for charismatic megafauna, as identified above. The good news is that this may be broadly consistent with the wellbeing potential of the different species. However, there is also a danger of anthropomorphism here, in that people appear to care more about species exhibiting similar physical, behavioural or cognitive features to ourselves (Harrison and Hall, 2010). An example is the "baby face" of the panda. Other biases may include a focus on easily identifiable victims, scope insensitivity (i.e., valuing similarly 10 or 1,000 birds saved) and proportion dominance (i.e., preferring to save lives in a smaller population, see Bartels, 2006). More generally, there is ample evidence of ineffective altruism, as people seem particularly concerned by their self-image or social image instead of maximising the impact of giving (Burum et al., 2020).

Metrick and Weitzman (1998) stress that "...we have to make up our minds here what it is we are optimizing. This is the essential problem confounding the preservation of biodiversity today". Along this line, Baumgärtner (2005) recognizes that “...the measurement of biodiversity requires a prior normative judgment as to what purpose biodiversity serves in ecological-economic systems". I agree. Nevertheless, I do disagree with the underlying current normative judgments in the economics of biodiversity, as they are all anthropocentric. From the point of view of the wellbeing of an individual, the fact that its own species is (or is not) at risk of extinction is irrelevant. To illustrate, we should provide care for affected birds covered in oil due to an oil spill, even if they do not belong to an endangered species (Bekoff, 2010). In summary, I argue that setting priorities regarding the lives of sentient beings based only on what they bring to the utility to humans is morally dubious. There exist strong moral reasons why we should preserve some species, and these moral reasons are not equal across species. Typically, more weight should be given to sentient animals, and especially those with greater wellbeing potential. This aspect should in turn be properly accounted for when setting any priorities regarding endangered species.

\subsection{Invasive species}


Invasive species are often considered as one of the primary causes of biodiversity loss (see, in particular, Chapter 19). The Review states that (page 462) “...invasive non-native species (INNS) are major drivers of biodiversity loss at a global level", and that "...increasing dominance of a few invasive species increases global homogenisation of biodiversity, reducing local diversity and distinctiveness." It emphasizes the benefits of control or the eradication of invasive species: "Some INNS have been successfully eradicated, with substantial benefits to native species, particularly on islands (Jones et al., 2016). For example, rat eradication was undertaken on Great Bird Island, one of Antigua's offshore islands, which is home to the world's rarest snake, the critically endangered Antiguan racer (Alsophis antiguae). The eradication resulted in the population of this snake increasing 20 times on four islands".

My argument here is simple. Although invasive species often significantly affect native ecosystems and our economy, the methods used to eradicate invasive species raise major animal welfare concerns. Invasive mammals, such as goats on the Galapagos or feral cats on remote islands, have suffered greatly during eradication campaigns (Sekar and Shiller, 2020). Current methods cause stress, trauma, and suffering for the animals involved, and most often death. For example, yellow phosphorous, which is used to kill feral pigs, damages the gastrointestinal tract and liver resulting in a death that takes several days to occur. Chloropicrin, a warren fumigant for the control of exotic European rabbits in Australia and New Zealand, generates headaches, nausea, diarrhoea, and respiratory obstruction, causing some rabbits to take up to several days to die (Marks, 2009). Even softer control methods, such as trapping, moving, containing, or confining can generate a marked level of pain and stress. While such treatments are used in sizeable campaigns targeting a large number of animals, the wellbeing impact of pest control measures has in general been neglected.

Therefore, there is a need to find a balance between the benefits of managing invasive species for biodiversity purposes and the loss in welfare of the animals involved. The desire of many environmentalists to retrieve original ecosystem equilibria should be carefully evaluated against its impact on the wellbeing of species currently living in these ecosystems. At the very least, it is important to take steps to minimize unnecessary and unintentional negative impacts on animal welfare, while working towards an ideal of zero suffering (Littin, 2010). More generally, we must factor compassion into decisions regarding invasive species. 
Bekoff (2010) summarizes this approach as follows: "The guiding principles of compassionate conservation are: do no intentional harm; respect all life; treat all individuals with respect and dignity; and tread lightly when stepping into the lives of animals".

Finally, the Review reminds us that humans have, more often than not, brought about the problem in the first place, stressing that, for instance (page 382) “...there is a strong positive relationship between the degree of international trade in countries and the number of invasive species". Indeed, much of the harm experienced by wild animals is associated with our attempts to redress what we have done to the planet and its occupants, both human and otherwise (Beausoleil, 2020). This responsibility suggests that we may have an additional moral obligation to treat invasive species humanely.

\section{Reducing meat consumption: A silver bullet?}

The previous section highlighted differences in the practical policy implications of anthropocentric and non-anthropocentric objectives. In this section, I now highlight one important example that largely satisfies both objectives; namely, the reduction of the production of animals for human consumption. Although animal agriculture is critical to the subsistence of smallholders in some poor countries, the global detrimental impact of animal farming is now well documented and somewhat overwhelming. More importantly for my purpose, the impact of animal agriculture on biodiversity is immense, as well as on the wellbeing of animals. To reduce this impact, a shift in the diet of humans towards more plant-based food seems remarkably efficient, particularly in developed countries.

The reduction in meat consumption is considered by many as the primary lever to reduce biodiversity loss (Machinova et al., 2015). Published the same week as the Review, a report from Chatham House (2021) entitled "Food system impacts on biodiversity loss", emphasizes that the first lever is indeed to change dietary patterns to reduce food demand and stimulate more plant-based diets. Meat consumption is a key driver for biodiversity loss because of the induced habitat loss. Indeed, the Review states that (page 105) "human induced habitat destruction is today the leading cause of species extinction." Notably, this destruction is mainly due to agriculture, and animal agriculture represents about $80 \%$ of agricultural land worldwide (Poore and Nemecek, 2018). Therefore, the production of animal-based food largely drives the use of land. In addition, both livestock and animal feed 
production are increasing in developing tropical countries where the majority of biological diversity is found (Machinova et al., 2015). Animal agriculture is linked to more than $85 \%$ of deforestation in Amazonia through pasture and animal feed (De Sy et al., 2015). Moreover, due to the loss in food conversion through animals, animal feed represents a net drain on the world's potential food supplies (Foley et al., 2011). Further, animal agriculture contributes significantly to other major issues, such as air pollution, climate change, water use, and eutrophication (Domingo et al., 2021; Poore and Nemecek, 2018; Springmann et al., 2018), as well as infectious diseases (Espinosa et al., 2020). All of these externalities may have indirect negative impacts on biodiversity.

In his foreword to the Review, David Attenborough eloquently raises the issue of animal farming (see data in Bar-on et al., 2015): "Today, we ourselves, together with the livestock we rear for food, constitute $96 \%$ of the mass of all mammals on the planet. Only $4 \%$ is everything else - from elephants to badgers, from moose to monkeys. And $70 \%$ of all birds alive at this moment are poultry - mostly chickens for us to eat." Although the issue of animal farming is not a focal point of the Review, it is discussed on some occasions, especially in the Review's last sections. For instance, it states that (page 398) "...cattle pasture contributed to the largest agricultural land expansion in South and Central America" and that (page 446) the "...over-exploitation of animals, plants and other wildlife has continued to drive biodiversity loss. It is the greatest cause of loss in the seas, principally through fisheries, and the second greatest on land".

What about the impacts of meat consumption on farm animals? First, farm animals are usually considered to be sentient (Broom, 2015). Clearly, animal farming raises important welfare concerns for animals, especially with modern agricultural practices. Most animals are raised intensively (about 99\% of them in the USA), meaning that they are confined indoors with hundreds or thousands of other animals during their entire lifetime (except during the final transport to the slaughterhouse). A large proportion of hens are raised in cages, for example. Most animals are routinely mutilated; for instance, pigs are castrated, cows are dehorned, chickens are debeaked, lamb are tail docked, and so on. In the dairy industry, cows are repeatedly inseminated, and usually separated from their calves just after birth. Essentially, all farmed animals are eventually slaughtered, often without the stunning process. There is little doubt overall that animal farming induces immense animal suffering 
in our world, with about 80 billion terrestrial animals raised and killed every year for our food, with a much higher number when counting marine animals.

The regulation of animal production, both in terms of environmental impacts and animal welfare, may thus help to significantly improve biodiversity and global welfare. However, such a regulation is costly, and difficult to implement in general. The failure over the decades of the greening of the Common Agricultural Policy illustrates this regulatory challenge (Pe'er et al., 2014). Hence, it may be more efficient to directly target food consumers than producers (Poore and Nemecek, 2018; Bonnet et al., 2020). In this context, as recognized by the Chatham House report (2021), it is central to encourage dietary shifts toward more plant-based food. However, there are also strong limitations to dietary changes, as it is difficult to change ingrained food habits. Our attraction to meat is evolutionarily hard-wired, since meat has a higher nutritional value than most crops, vegetables, or fruit. Furthermore, meat consumption and pro-meat beliefs are permanently reinforced by our existing social norms, values, and policies (Nyborg et al., 2016). The Review rightly emphasizes the importance of conformism in general (page 232, and Annex 9.1), and this aptly applies to dietary habits. Given these economic, behavioural, and political hurdles, the Review also thoughtfully emphasizes the importance of innovations as a possible solution in this domain. It states that (page 415) "...producing meat and meat-like products without animal agriculture is a rapidly growing field, with the potential to reduce significantly land use and environmentally damaging inputs (compared with conventional meat production). Cellular agriculture and plant-based meat are the two major meat analogues."

\section{Anthropocentrism in academia}

Anthropocentrism is prevalent in academia. As already stated, this is the case in economics where essentially all research is anthropocentric (Carlier and Treich, 2020). Note that this is also the case in environmental and resource economics, and in ecological economics. Common and Stagl (2005) state, for instance, that "...there is no difference at all between ecological economics and neoclassical economics. Both are anthropocentric, as well as utilitarian." Costanza et al. (1991) also make it clear that sustainability is a human-centred notion: "Sustainability is a relationship between human economic systems and larger dynamic, but normally slower-changing, ecological systems in which 1) human life can continue indefinitely, 2) human individuals can flourish, and 3) human cultures can develop; 
but in which effects of human activities remain within bounds, so as not to destroy the diversity, complexity, and function of the ecological life support system."

The situation is quite different in the field of conservation biology, as many have criticized anthropocentrism and have favoured other approaches, such as ecocentrism (Taylor et al., 2020). Nevertheless, anthropocentrism remains widespread in this field (Kopnina et al., 2018), and the issue of animal wellbeing has been overlooked by many conservationists. Ramp and Bekoff (2015) emphasize that the discussions on how best to protect Nature "...have primarily been targeted at species and ecosystems for success, without explicitly expressing concern for the intrinsic value and welfare of individual animals. In part, this is because animal welfare has historically been thought of as an impediment to conservation." Michael Soulé, widely credited with starting the field of conservation biology, writes (cited in Fraser, 2010): "Although disease and suffering in animals are unpleasant and, perhaps, regrettable, biologists recognize that conservation is engaged in the protection of the integrity and continuity of natural processes, not the welfare of individuals. ... Conservation and animal welfare ...are conceptually distinct, and they should remain politically separate." I can imagine various reasons that may explain this academic bias. In life sciences, focusing on animal wellbeing may be viewed as too subjective or too emotional, and inconsistent with scientific objectivity (Webb and Huchard, 2020). Bekoff (2010) states this clearly: “...compassion, sentimentality and anthropomorphism have no place in conservation, the argument goes". The difficulty of the topic may also contribute. Although it is already difficult to obtain quantitative measures about populations of animals, this seems much easier than obtaining a reliable measure of the wellbeing of the individual animals in those populations. Additionally, it seems much simpler to target the maintenance of an ecosystem state as a policy objective than to estimate the wellbeing of all sentient species living in that ecosystem for each policy scenario.

Besides this, in economics, we know how difficult it is to measure welfare. Obtaining reasonable welfare estimates with regard to animals seems much more challenging than for humans (see the next section for more arguments). Our standard pricing or "willingness-topay" methods in policy evaluation (cf. Chapters 11 and 12) would, at the least, require some significant adjustment, if not a complete reconsideration. For instance, Johansson-Stenman (2018) formally shows how the crucial concept of Pareto efficiency, as well as monetary 
welfare measures, in terms of private and social willingness-to-pay must be modified in a world where animal welfare is intrinsically taken into account. Moreover, interdisciplinary collaboration is likely required, for instance with animal ethics experts, thus adding the usual difficulties of crossing disciplinary boundaries.

A simple hypothesis to explain academic anthropocentrism is the bias we may have as humans. Indeed, we naturally have a bias in favour of our own species, and this may explain common speciesism and biased moral intuitions (Jacquet, 2021). In common thinking and colloquial discussions, we tend to keep our species distinctly separate from others, for instance, in our day-to-day language. Moreover, our research agenda is inevitably shaped by political forces fully controlled by humans. Indeed, the relative attention given to animal welfare seems much more advanced in the philanthropic arena than in academia. Some conflicts of interest may also play a role. Agricultural economists have strong ties with the agricultural sector, and perhaps have consequently limited incentives to focus on issues related to biodiversity loss (largely due to agriculture), or to farm or wild animal welfare. Political beliefs or worldviews may also matter. Many of those who are interested in the environment seem to have an idyllic view of natural processes (Horta 2010a), thus perhaps downplaying animal suffering in Nature and in turn the need for human action in this domain.

There is also evidence of cognitive dissonance regarding animal welfare amongst the public as well as in academia (Plous, 1993; Loughnan et al., 2010; Espinosa and Treich, 2020); that is, lay people as well as researchers may undermine the reality of animal suffering possibly because they feel guilty as they participate directly or indirectly in forms of animal exploitation. Meat eating is a case in point, even for environmentalists (Scott et al., 2019). Shekan and Shiller (2020) note for instance that “...conservation organizations and conservationists themselves (like other environmentalists) often regularly purchase factory farm products even though factory farms pose serious concerns about human induced animal suffering." Essentially, I consider that researchers are simply "normal people", and they may share common perception biases that in turn influence their research agenda. If researchers undermine the issue of animal wellbeing in general, this reduces their perception of the importance of the topic, and their incentives to work on it. 
Finally, the Review eloquently emphasizes how we tend to neglect what is invisible and silent (cf. Chapters 2 and 4), and how we are influenced by our past choices and social networks (cf. Chapter 9). The Review suggests that this may explain why we often ignore environmental problems. I agree with this but would add that this may also explain why we ignore the wellbeing of wild animals. Along this line, some outcomes may be due to a deficiency in education. The Review rightly observes that (page 498) "...it is a cruel irony that we surround children with pictures and toys of animals and plants, only to focus subsequently on more conceptual knowledge, marginalising environmental education relative to the wider curriculum." Targeting younger generations may have a more significant impact, particularly because the young have a more malleable cognitive process. Further, a change in the actions of the young has a longer impact over time. The Review stresses the importance of (page 498) "...establishing the natural world within educational policy". I fully agree but would also stress the interest of including some specific knowledge from animal sciences and animal ethics into the curriculum.

\section{Some non-anthropocentric research directions}

In this section, which borrows from Carlier and Treich (2020) and Fleurbaey and Leppanen (2021), I present some possible non-anthropocentric research directions that may be pertinent in the economics of biodiversity and in economics more generally. Note, however, that this section is largely influenced by my own personal interests and biases, and certainly limited by my ability to foresee interesting research topics into the future. In any case, the overarching message is that the research potential is enormous. Anthropocentrism is a major limitation in economics research, and it is surprising that this topic has been almost completely overlooked, especially in social choice and environmental and resource economics.

\subsection{Normative issues}

Since the normative approach proposed in this paper includes the wellbeing of animals, this approach requires us first to define and measure animal welfare. A starting point for this is to build on the animal sciences that use various indicators for welfare (to date, mostly applied to domestic animals), such as the rate of mortality or injuries, impaired growth, heartrate change, the reproductive or immune systems, measures of stereotypes and self- 
narcotization, or stress hormone levels (Broom, 2014). See Browning (2020) for an overview of different measures of animal welfare. Systems such as the "five freedoms", and related approaches such as the Welfare Quality ${ }^{\circledR}$ protocol and SOWEL-type models, also provide some useful guiding principles, however, with severe limitations (Mellor, 2006; Browning, 2020). One important challenge is to capture the positive experiences of animals. Another is to understand how to value the loss of life, as some have argued that animals' limited future projection capacities may reduce this value when animals are replaceable (Singer, 2011). Interestingly, a small body of literature in animal sciences uses a revealed preferences approach as in economics, where the preferences of animals are inferred from their choices (Mason et al., 2001; Dawkins, 2003).

The capacity for subjective experience and quality of life is likely to differ greatly across various wild animal populations. For instance, it is important to understand when and how animals die, or how population density affects wellbeing, which has not often been the focus of research in biology or ethology. $\mathrm{Ng}$ (1995) proposes to define a new field at the intersection of social choice and biology, coined "welfare biology", that studies the welfare of living things with the tools of evolutionary biology, population dynamics, and economics. As a first step, he defines welfare as "enjoyment minus suffering", and first observes that enjoyment or suffering are costly in terms of energy requirements, explaining why we feel neutral most of the time. He then suggests diminishing marginal returns to both enjoyment and suffering, and that the cost of suffering is likely to be greater than the gain due to enjoyment in absolute terms. This approach relates to studies at the interface of biology and economics that identify plausible humans' utility functions (Robson, 2001; Alger and Weibull, 2019). Further works in this vein may help to identify plausible utility functions for animals.

An important issue for social choice experts concerns the aggregation of wellbeing measures. A possibility is to make an aggregation within each population of animal species, extending across all populations. This raises the question of how inequality-sensitive social welfare functions would apply to heterogeneous species (Fleurbaey and Maniquet, 2011; Adler, 2012). ${ }^{15}$ While comparing welfare among humans remains difficult and debated in social choice, it is important to again acknowledge the immense difficulty of welfare

\footnotetext{
${ }^{15}$ Note, moreover, that the appropriate individual unit is not so clear, especially if the moral circle extends beyond animals (Fleurbaey and Leppanen 2021).
} 
comparisons between humans and animals, and among animals themselves. Indeed, comparing individuals from different species appears much more difficult than comparisons among humans because of the larger differences in abilities, needs, and goals. In this paper, I have adopted the standard individualist and consequentialist method of welfare economics. Fleurbaey and Leppanen (2021) discuss a handful approaches to the measurement of wellbeing under this method. Interestingly, they challenge the hedonic approach where happiness is the unique and ultimate goal. Clearly, other non-consequentialist approaches are also possible, as briefly discussed in Section 2. In particular, an important issue concerns our moral responsibility. Some would believe, for instance, that it is not our moral responsibility to protect wild animals, so that it is questionable to think that their welfare is our responsibility when designing a biodiversity policy (McShane, 2018).

In practice, some animal charities are currently computing "moral weights" on animals to identify priorities in philanthropy. ${ }^{16}$ Relatedly, Browning (2020) presents a list of "suffering calculators" that have been put forward by various animal welfare experts. Budolfson and Spears (2020) propose estimating moral weights with the number of neurons in the brain of an average member of a species. With this assumption, they estimate that a human life year is worth about 344 mammal life years and about 10,700 fish life years. Budolfson and Spears' approach is flexible enough so that the weights could increase sharply (or only mildly increase) with the number of neurons. They acknowledge that the number of neurons is a crude indicator of the abilities of the brain; see Broom (2014) and Carlier and Treich (2020) for a discussion. At the very least, this is an interesting starting point. Fleurbaey and Leppanen (2021) argue, however, that there is a fundamental difficulty in comparing feelings across species with different brains and different bodies, as well as different evolutionary histories. They discuss possible normalization methods to compare wellbeing levels across species.

7.2 Adjusting environmental and agricultural policies

Another research direction concerns policy evaluation methods, such as benefit-cost analysis (BCA). The integration of non-anthropocentric objectives in BCA remains an important blind spot. Stawasz (2020) argues that valuing animals may (and should) matter in policy making

\footnotetext{
${ }^{16}$ See, for example, https://forum.effectivealtruism.org/tag/moral-weight.
} 
but emphasizes the lack of existing methodology. Regulatory agencies often ignore some impacts when valuation methods are judged to be theoretically unsound (Budolfson and Spears, 2020), which suggests a circularity problem. A promising direction may be to extend the quality adjusted life year (QALY) approach to animals. Another direction concerns the extension of the social welfare function approach (Adler, 2012). Note that some implications may be profound. As an example, once animals are integrated into the social objective, it is not clear how to deal with humans who gain pleasure from hunting, killing, or eating animals. Amartya Sen, John Harsanyi and others have argued that the government should not respect "anti-social preferences" (Johansson-Stenman, 2018).

A central topic in environmental economics concerns property rights. The Review emphasizes that (page 191) "...human activities involving the biosphere (in other words, all human activities) give rise to externalities because property rights to large segments of the biosphere are either weakly defined or inadequately enforced". Property rights may help animals. These rights have contributed to saving the American bison from extinction and to mitigating overfishing with some success. Animal ownership creates incentives to take care of animals and to limit damages caused to others by the owned animal. However, property rights also generate incentives to pursue the exploitation of sentient animals, an objective that is generally not aligned with animal welfare (Carlier and Treich, 2020). The works of animal rights scholars, such as Regan (1983), suggest that property rights are the most important force leading to the exploitation of animals and their resulting poor welfare. The intersection of property rights, biodiversity management, and animal welfare is worth further investigation in economics.

Many applications of a non-anthropocentric approach can be envisioned in the field of applied microeconomics. To the best of my knowledge, the existing handful of applications all use a utilitarian setting, where non-human species have some weight in the utilitarian social welfare function. In fact, as argued in Section 2, this illustrates that a fairly minor departure from the standard normative setting used in economics may already provide some insights. Let me first mention the seminal contribution of Blackorby and Donaldson (1992). In this early paper, the authors formally study the optimal use of animals. They consider two applied topics: animal testing and meat consumption. In their model, the social planner makes decisions that determine the level of animal wellbeing, as well as the number 
of animals that are exploited. This is thus an exercise in population ethics. In their second application, they show that "direct controls" (which can be conceived as animal welfare legal standards) are in general necessary on top of meat taxation. They also show that the Paretoefficient allocations cannot in general be decentralized as competitive equilibria: specifically, the second theorem of welfare economics does not hold. This important early study reminds us that not much has been written since on the optimal regulation of animal welfare.

Building on a similar model to Blackorby and Donaldson (1992), Espinosa and Treich (2021) show that the optimal consumption of animals increases with the moral weight on animals in the utilitarian social welfare function if and only if animals' utility is positive. That is, the critical condition is whether farm animals' lives are worth living. By empirically exploring the critical condition by means of a survey, they show the divergence of opinions between experts and the public (farm animal experts vs. students), within the public (students vs. animal activists), as well as between experts themselves (farm animal experts vs. animalethics experts). Along this line, Kuruc and McFadden (2021) embed animal welfare into a climate-economy with an agricultural sector. Under some parameterization of the social welfare function that assumes that farm animal lives are worse than non-existence (consistent with the data of Espinosa and Treich), they show that the optimal policy is driven by animal welfare costs, and not by the costs of climate externalities.

This last study focusses on the impact of animal agriculture on climate change, however, this raises the important reverse causality question of the impact of climate change on animals. McShane (2018) argues that animal ethics has been neglected in climate policy discussions, for instance by the reports of the Intergovernmental Panel on Climate Change (IPCC). Yet, the impacts on animals are expected to be vast. A change in temperature strongly affects habitats, and some animals will have to adjust to new seasonal cycles. Extreme weather events can displace animal populations. Exposure to parasites and diseases may also change. There may be positive effects, at least for some animals, for instance on insects. Indeed, climate change may favour r-selected species over K-selected species (Sebo, 2021). Some animals may have access to new food or face fewer predators. McShane (2018) also emphasizes the indirect effects: an increased reliance on biofuels, for example, is likely to increase human incursions into animal habitats. 
More generally, the design of agricultural policy is central. In particular, an important debate in biodiversity conservation concerns the choice between land sparing (i.e., high-yielding agriculture on a small land footprint) or land sharing (i.e., low-yielding wildlife-friendly agriculture on a larger land footprint); see Green et al. (2005). I simply note here that this choice matters a great deal for animals. For instance, the use of pesticides has a profound effect on animals (Littin, 2010). Small mammals often reach densities of more than 100 individuals per hectare on agricultural land, and most of these animals are strongly affected and often killed by certain agricultural practices, such as ploughing and harvesting (Fraser 2010). Hence, it could be interesting to introduce considerations regarding animal welfare into the land sharing and land sparing debate.

\subsection{Optimal intervention in the wild}

The management of biodiviersity when animal wellbeing counts raises the fundamental question of human interventionism in Nature. Many scholars argue that we should leave the Nature alone (Kymlicka and Donaldson 2011; Wilson, 2016), but others disagree. This question has already generated intense intellectual debate in the field of animal ethics (see Dorado 2015 for an overview). It is sometimes referred to the Reducing-Wild-AnimalSuffering (RWAS) movement in animal advocacy. ${ }^{17}$ This movement starts with the postulate that there is a lot of suffering in the wild ( $\mathrm{Ng}, 1995$; Horta, 2010b). The main idea behind this postulate is that natural selection benefits the maximization of the number of offspring, rather than the wellbeing of the offspring (Dawkins, 1995; Clarke and Ng, 2006). Indeed, the overwhelming majority of animals are r-selected species (see Box 2.2 in the Review), and the quasi-totality of these animals die shortly after their birth or hatching. Most often they starve or are eaten alive.

This postulate of high wild animal suffering therefore suggests that it could be legitimate for humans to intervene in Nature in order to reduce this suffering, in a similar fashion as a benevolent social planner would reduce inequality or negative externalities in the standard approach. The intervention may consist of assistance to animals in need, as well as more intrusive actions such as vaccination or sterilization campaigns. Another, perhaps much

\footnotetext{
${ }^{17}$ As an example, see this website on the effective altruism movement: https://forum.effectivealtruism.org/posts/rACbNFfdQBfnj65ZX/reducing-wild-animal-suffering-ecosystem-anddirectory.
} 
more ambitious, proposal is to intervene in the wild in order to reduce predation (Cowen, 2006; Horta, 2010a,b,c), a topic which is related to the reintroduction of wolves discussed earlier. Johannsen (2020) readily suggests using genetic techniques, such as CRISPR, to reduce the fertility of some species, or their ability to suffer, or even to alter the diet of predators. Note that, at the extreme, if wild animal lives are not worth living, habitat destruction leading to biodiversity loss may not even be a curse.

Whether and how to intervene to maximize global welfare is thus an important area of future research. The early studies of Eichner and Pethig (2006) and of Clarke and Ng (2006) already begun such an exploration in economics. Eichner and Pethig consider an integrated dynamic model of the economy and the ecosystem with competition between human and non-human species for land and prey biomass, and where nonhuman species also have a moral value. Clarke and $\mathrm{Ng}$ (2006) model the interaction between population dynamics and welfare maximization for animals. More precisely, they study the optimal birth rate that maximizes animal welfare under different assumptions regarding the population growth rate in the case of a single animal population. They show that optimal birth rates are lower in the case of welfare maximization vs. growth maximization. They also explore the case of competing populations in a Lotka-Volterra model. In this model, the choice of birth rates does not affect the population sizes at equilibrium. Hence, the point is that welfare could be higher with a lower birth rate, thus suggesting that human intervention to reduce this rate is justified in principle.

These economic settings could be extended in various directions. Multiple species (with different sizes and different wellbeing potentials), different welfare criteria, different population dynamics and various interactions (predator-prey, symbiosis etc.), and different economic environments can be considered in order to explore the laissez-faire equilibria and the optimal policy. Further studies can also include some political economy issues. One obvious central issue is that animals do not have political power (i.e., they do not vote). Hence, they should have no weight in the policy decisions since these decisions are practically administered by humans. To explain pro-animal policy outcomes, we must return to an anthropocentric approach where what matters is whether some humans care about some animals and how. Unless people are pure altruists toward animals, policy outcomes 
should not in principle maximize global welfare. Note the similarity of this question with that concerning the treatment of future generations (Marglin, 1963; Feinberg, 1974).

\section{Conclusion}

Gruen and Jamieson (cited in Persson 2008) claim that "...we do not have a good philosophical account of why biodiversity matters". Although the Dasgupta Review (Dasgupta 2021 ) is an invaluable study on the economics of biodiversity, it does not provide such a "good philosophical account". The main fault is that the Review adopts a human-centric worldview, as it assumes that all other beings are a means to human ends. Thus, it does not consider the externalities of human actions on the wellbeing of non-humans. In failing to do so, the Review misses what matters most morally about biodiversity. In a recent paper, Fleurbaey and Leppanen (2021) incisively criticize such an anthropocentric approach: “...just as the balance sheet of plantations should have accounted for the conditions endured by slaves, farming and various land uses should be analyzed including the impact on domesticated animals and wildlife."

Viewed objectively, the Review simply follows the standard approach in economics, as the possibility of non-anthropocentric objectives has rarely been explored. However, such an exploration becomes necessary and urgent given our global wellbeing footprint on Earth. Moreover, it has the potential to be extremely rewarding, as the consequences of relaxing the anthropocentric assumption seem vertiginous in terms of research possibilities. To paraphrase Frank Ramsey, cited in the Review (page 261), the current practice of ignoring non-humans' welfare is "ethically indefensible" and "...arises merely from the weakness of the imagination". As Johansson-Stenman (2018) forcefully argues, it is time to change this practice. It is time to imagine a different economic approach to biodiversity where the wellbeing of other sentient beings matters.

\section{References}

Adler M (2012) Well-being and Fair Distribution: Beyond Benefit Cost Analysis. Oxford University Press.

Alger I, Weibull JW (2019) Evolutionary models of preference formation. Annual Review of Economics 11: 329-54. 
Ando A, Langpap C (2018) The economics of species conservation. Annual Review of Resource Economics 10:445-467.

Baars B (2001) There are no known differences in brain mechanisms of consciousness between humans and other mammals. Animal Welfare 10(1):31-40.

Bar-on YM, Philips R, Milo R (2018) The biomass distribution on Earth. Proceedings of the National Academy of Sciences. 115(25): 6506-11.

Bartels D (2006) Proportion dominance: The generality and variability of favoring relative savings over absolute savings, Organizational Behavior and Human Decision Processes 100:76-95.

Baumgärtner S (2005) Measuring the diversity of what? And for what purpose? A conceptual comparison of ecological and economic biodiversity indices. Available at SSRN:

\section{https://ssrn.com/abstract=894782.}

Beausoleil NJ (2020) I am a compassionate conservation welfare scientist: Considering the theoretical and practical differences between compassionate conservation and conservation welfare. Animals 10(2):257.

Bekoff M (2010) First do not harm. New Scientist, 28 August.

Bentham J (1780) An Introduction to the Principles of Morals and Legislation.

https://www.econlib.org/library/Bentham/bnthPML.html.

Blackorby C, Donaldson D (1992) Pigs and guinea pigs: A note on the ethics of animal exploitation. Economic Journal 102:1345-69.

Bonnet C, Bouamra-Mechemache Z, Réquillart V, Treich N (2020) Regulating meat consumption: How to improve health, the environment and animal welfare. Food Policy 97 101847.

Broom D (2014) Sentience and Animal Welfare. CABI Publishing.

Brown C (2015) Fish intelligence, sentience and ethics. Animal Cognition 18:1-17.

Browning $H(2020)$ Assessing measures of animal welfare, mimeo.

Budolfson M, Spears D (2020) Public policy, consequentialism, the environment, and nonhuman animals, The Oxford Handbook of Consequentialism (ed. DW Portmore), Oxford University Press.

Burum B, Nowak MA, Hoffman M (2020) An evolutionary explanation for ineffective altruism. Nature Human Behavior 4:1245-1257. 
Callicott JB (1989) In Defense of Land Ethic: Essays in Environmental Philosophy. Albany: State University of New York.

Carlier A, Treich N (2020) Directly valuing animal welfare in (environmental) economics. International Review of Environmental and Resource Economics 14: 113-52.

Carpendale M (2015) Welfare biology as an extension of biology: Interview with Yew-Kwang Ng. 10.7358/rela-2015-002-carp.

Ceballos G et al (2015) Accelerated modern human-induced species losses: Entering the sixth mass extinction. Science Advances 1(5) e1400253.

Clarke M, Ng Y-K (2006) Population dynamics and animal welfare: Issues raised by the culling of kangoroos in Puckapunyal, Social Choice and Welfare 27:407-22.

Clinchy M, Sheriff MJ, Zanette LY (2013), Predator-induced stress and the ecology of fear. Functional Ecology, 27:56-65.

Common M, Stagl S (2005) Ecological Economics: An Introduction. Cambridge University Press.

Costanza R, Daly H, Bartholomew J (1991) Goals, agenda and policy recommendations for ecological economics. In: Ecological Economics: The Science and Management of Sustainability. Ed. By R Costanza. NY: Columbia University Press.

Cowen T (2003) Policing nature. Environmental Ethics. 25(2): 169-82.

Dasgupta P (2021) The Economics of Biodiversity: The Dasgupta Review. London: HM Treasury.

https://assets.publishing.service.gov.uk/government/uploads/system/uploads/attachment data/file/962785/The Economics of Biodiversity The Dasgupta Review Full Report.pdf

Dawkins R (1995) God's utility function. Scientific American 247:80-5.

Dawkins MS (2004) Using behavior to assess animal welfare, Animal Welfare 13, 3-7.

De Sy V et al (2015) Land use patterns and related carbon losses following deforestation in South America. Environmental Research Letters 10124004.

Domingo NGG et al (2021) Air quality-related health damages of food. Proceedings of the National Academy of Sciences 118 (20) e2013637118.

Dorado D (2015) Ethical interventions in the wild - An annotated bibliography. Relations 3.2. Edelman D, Baars B, Seth AK (2005) Identifying hallmarks of consciousness in nonmammalian species. Consciousness and Cognition 14(1):169-87. 
Eichner T, Pethig R (2006) Efficient nonanthropocentric nature protection. Social Choice and Welfare 26:47-74.

Espinosa R, Treich N (2021) Animal welfare: antispeciesism, veganism and a "life worth living". Social Choice and Welfare 56:531-548.

Espinosa R, Tago D, Treich N (2020) Infectious diseases and meat production, Environmental and Resource Economics 76:1019-44.

Estrada A et al (2017) Impending extinction crisis of the world's primates: Why primates matter. Science Advances 3(1) e1600946.

Feinberg J (1974) The rights of animals and unborn generations. In Philosophy and Environmental Crisis, by WT Blackstone (ed.), 43-68. Athens, GA: The University of Georgia Press.

Fleurbaey M, Leppanen C (2021) Toward a theory of ecosystem well-being. Journal of Bioeconomics https://doi.org/10.1007/s10818-021-09315-x

Fleurbaey M, Maniquet F (2011) A Theory of Fairness and Social Welfare. Cambridge University Press.

Foley JA et al (2011) Solutions for a cultivated planet. Nature 478:337-42.

Fraser D (2010) Toward a synthesis of conservation and animal welfare science, Animal Welfare 19:121-24.

Ginsburg S, Jablonka E (2019) The Evolution of the Sensitive Soul: Learning and the Origins of Consciousness. MIT Press.

Green RE, Cornell JS, Scharlemann JPW, Balmford A (2005) Farming and the fate of wild nature, Science 28:550:55.

Greggor AL et al (2016) Research priorities from animal behaviour for maximising conservation progress, Trends in Ecology \& Evolution 31(12):953-964.

Griffin D (1978) Prospects for a cognitive ethology. Behavioral and Brain Sciences 1, 527-538. Groom B, Turk Z (2021) Reflections on the Dasgupta Review on the economics of biodiversity. Environmental and Resource Economics 79:1-23.

Gruen L (2017) The moral status of animals. In: The Stanford Encyclopaedia of Philosophy. Harrison MA, Hall AE (2010) Anthropomorphism, empathy, and perceived communicative ability vary with phylogenetic relatedness to humans. Journal of Social, Evolutionary, and Cultural Psychology, 4(1):34-48. 
Horta O (2010a) Debunking the idyllic view of natural processes. Population dynamics and suffering in the wild. Telos. 17(1): 73-90.

Horta O (2010b) What is speciesism? Journal of Agricultural and Environmental Ethics 23:243-66.

Horta $O$ (2010c) The ethics of the ecology of fear against the nonspeciesist paradigm: A shift in the aims of intervention in nature. Between the Species 13:163-187.

IPBES (2019) Summary for Policymakers of the Global Assessment Report on Biodiversity and Ecosystem Services of the Intergovernmental Science-Policy Platform on Biodiversity and Ecosystem Services.

Jacquet F (2021) Speciesism and tribalism: embarrassing origins. Philosophical Studies https://doi.org/10.1007/s11098-021-01700-6

Johansson-Stenman O (2018) Animal welfare and social decisions: Is it time to take Bentham seriously? Ecological Economics 145(C):90-103.

Johannsen K (2020) Wild Animal Ethics: The Moral and Political Problem of Wild Animal Suffering. Routledge.

Kopnina H, Washington H, Taylor B, Piccolo JJ (2018) Anthropocentrism: More than just a misunderstood problem. Journal of Agricultural and Environmental Ethics 31:109-127. Kuruc K, McFadden J (2021) Monetizing the externalities of animal agriculture: Insights from an inclusive welfare function. Mimeo.

Kymlicka W, Donaldson S (2011) Zoopolis: A Political Theory of Animal Rights. Oxford University Press.

Leopold A (1949) A Sand County Almanach: And Sketches Here and There. Oxford University Press.

Littin KE (2010) Animal welfare and pest control: Meeting both conservation and animal welfare goals. Animal Welfare 19:171-76.

Low P, Panksepp J, Reiss D, Edelman D, van Swinderen B, Koch C (2012) The Cambridge declaration on consciousness. Presented at the Francis Crick Memorial Conference, Cambridge, England.

Loughnan S, Haslam N, Bastian B (2010) The role of meat consumption in the denial of mind and moral status of animals. Appetite 55:156-159.

Marglin SA (1963) The social rate of discount and the optimal rate of investment, Journal of Political Economy 77:95-111. 
Marks CA (2009) Fumigation of rabbit warrens with chloropicrin produces poor welfare outcomes - a review. Wildlife Research 36(4):342-352.

Martin-Lopez B, Montes C, Benayas J (2008), Economic valuation of biodiversity conservation: The meaning of numbers. Conservation Biology 22:624-635.

Mason G, Cooper J, Clarebrough C (2001) Frustrations of fur-farmed mink. Nature 410:35-36. McShane K (2018) Why animal is not biodiversity, ecosystem services, or human welfare: Toward a more complete assessment of climate impacts. The Ethics Forum 13(1):1-230. Mellor DJ (2016) Moving beyond the "five freedoms" by updating the "five provisions" and introducing aligned "animal welfare aims". Animals 6(10):59.

Metrick A, Weitzman ML (1998) Conflicts and choices in biodiversity preservation. Journal of Economic Perspectives 12(3):21-34.

Miralles A, Raymond M, Lecointre G (2019) Empathy and compassion toward other species decrease with evolutionary divergence time. Scientific Reports. 9: 19555.

Ng, Y-K (1995) Towards welfare biology: Evolutionary economics of animal consciousness and suffering. Biology and Philosophy. 10(3):255-85.

Norwood FB, Lusk JL (2011) Compassion, by the Pound: The Economics of Farm Animal Welfare. Oxford: Oxford University Press.

Nussbaum MC (2006) Frontiers of Justice: Disability, Nationality, Species Membership, Cambridge, Belknap Press.

Nyborg K et al (2016) Social norms as solutions. Science 354:42-43.

Pe'er G et al (2014) EU agricultural reform fails on biodiversity. Science 344:1090-1092. Persson E (2008) What is wrong with extinction? Lund University.

Plous S (1993) Psychological mechanisms in the human use of animals, Journal of Social Issues 49:11-52.

Poore J, Nemecek T (2018) Reducing food's environmental impacts through producers and consumers. Science 360:987-992.

Ramp D, Bekoff M (2015) Compassion as a practical and evolved ethic for conservation. BioScience 65:323-327.

Regan T (1983) The Case for Animal Rights. University of California Press.

Ripple WJ, Beschta RL (2004) Wolves and the ecology of fear: Can predation risk structure ecosystems? BioScience 54:123-38. 
Robson A (2001) Why would Nature give individuals utility functions? Journal of Political Economy 109:900-914.

Scott E, Kallis G, Zografos C (2019) Why environmentalists eat meat. PLoS One. 14, e0219607.

Seddon N et al (2016) Biodiversity in the Anthropocene: prospects and policy, Proceedings of the Royal Society B 283: 2016209420162094.

Sekar N, Shiller D (2020) Engage with animal welfare in conservation, Science 369:629-30.

Sebo J (2021) Saving Animals, Saving Ourselves. Oxford University Press.

Singer P (1975) Animal Liberation: A New Ethics of Our Treatment of Animals. Random House.

Singer P (2011) Practical Ethics. Third edition. Cambridge University Press.

Stawasz A (2020) Why and how to value nonhuman animals in benefit cost analyses? Mimeo.

Springmann M et al (2018) Health and nutritional aspects of sustainable diet strategies and their association with environmental impacts: a global modelling analysis with country-level detail,

The Lancet Planetary Health 2(10) e451-e461.

Taiz L, Alkon D, Draguhn A, Murphy A, Blatt M, Hawes C, Thiel G, Robinson DG (2019) Plants neither possess nor require consciousness. Trends in Plant Science. https://doi.org/ 10.1016/j.tplants.2019.05.008.

Taylor B, Chapron G, Kopnina H, Orlikowska E, Gray J, Piccolo JJ (2020) The need for ecocentrism in biodiversity conservation. Conservation Biology 34:1089-1096.

ten Cate C (2016). Assessing the uniqueness of language: Animal grammatical abilities take center stage. Psychonomic Bulletin \& Review 24:91-96.

Webb CE, Woodford P, Huchard E (2019) Animal ethics and behavioral science: An overdue discussion? BioScience 69:778-88.

Wilson EO (2016) Half-Earth: Our Planet's Fight for Life. Liveright Publishing Corporation. WWF (2020), Living Planet Report. https://www.wwf.fr/sites/default/files/doc-202009/20200910 Rapport Living-Planet-Report-2020 ENGLISH WWF-min.pdf 